\title{
PG - 45 : STUDY OF ASSISTED VENTILATION IN NEONATES AND ITS OUTCOME
}

\section{Reddy Prasad, Final year postgraduate, Department of Paediatrics,}

\section{Mahatma Gandhi Medical College \& Research Institute, SBV, Pondicherry}

Introduction: Mechanical ventilation has become a cornerstone in neonatal intensive care unit. Along with improving the outcome, morbidity and long term sequelae also has been a burden both for the parents and medical professionals. Hence it becomes necessary to evaluate the indications of ventilation, complications, outcome and long term comorbidities.

Objectives: This study was undertaken to find out the indications, complications, and outcome of neonates requiring assisted ventilation.

Methodology: It was a prospective observational study conducted at MGMCRI Hospital, Pondicherry - a tertiary care centre over a period of 1 year 9 months from October 2015 to July 2017. All the neonates who received Mechanical Ventilation in the Neonatal Intensive Care Unit (NICU) during the study period were included. We excluded the neonates with major congenital malformations, surgical conditions. Data were entered in a pre-designed proforma and morbidity and mortality were analyzed.

Results: Among 80 ventilated neonates, Hyaline Membrane Disease 28(35\%) and birth asphyxia $27(33 \%)$ were the commonest indication followed by Meconium Aspiration Syndrome (22.5\%). Female babies had a better survival rate $(96 \%)$ compared to male babies (76.4\%). Ventilated associated pneumonia was the commonest complication, followed by sepsis, shock, pulmonary hemorrhage, pneumothorax, bronchopulmonary dysplasia. Mortality in ventilated neonates was $17.5 \%$.

Conclusion: In our study, the survival rate of ventilated babies was $82.5 \%$. Hyaline membrane disease was the commonest indication of mechanical ventilation. Pulmonary hemorrhage, PPHN and IVH were significantly associated with a poor outcome. 